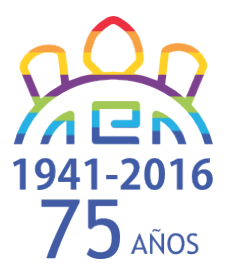

RMA

Arqueología

\title{
Un manuscrito inédito de Rudolf Schreiter sobre arqueología del noroeste argentino. Relaciones entre coleccionismo e investigación científica a comienzos del Siglo XX
}

\author{
An unpublished manuscript of Rudolf Schreiter on
} archaeology in northwestern Argentina. Relations between collectionism and scientific research in the early XXth century

\author{
Valeria Palamarczuk* y María Solange Grimoldi**
}

\begin{abstract}
* IDECU, Museo Etnográfico "Juan B. Ambrosetti", CONICET, Facultad de Filosofía y Letras, Universidad de Buenos Aires, Ciudad Autónoma de Buenos Aires, Argentina. e-mail: valepala@yahoo.com.ar

** Museo Etnográfico "Juan B. Ambrosetti", Facultad de Filosofía y Letras, Universidad de Buenos Aires, Ciudad Autónoma de Buenos Aires, Argentina.

e-mail: solgrimoldi@gmail.com
\end{abstract}

\begin{abstract}
Resumen
En el año 1912 Rudolf Schreiter concretó la venta de una colección de objetos arqueológicos de los valles calchaquíes al Museo de la corte real imperial de historia natural de Viena (actual Museo del Mundo de Viena). La transacción incluyó el envío de un catálogo, fotografías y un manuscrito en alemán que describía los trabajos de campo arqueológicos realizados en 1907. El manuscrito permaneció inédito hasta hoy; el presente ensayo monográfico es una introducción a nuestra traducción al castellano del manuscrito. Presentamos una síntesis de la historia de la conformación de diferentes colecciones reunidas por Schreiter en los valles calchaquíes, actualmente guardadas en museos de Argentina y Europa. Este repaso permite evaluar la escala de las transacciones de Schreiter y conocer las estrategias y vínculos mediante los cuales gestionó la adquisición y venta de grandes colecciones arqueológicas a lo largo de más de tres décadas.
\end{abstract}

Palabras clave: Colecciones arqueológicas; Museos; Noroeste argentino; Valles calchaquíes; Soporte documental de colecciones; Schreiter.

\begin{abstract}
In 1912 Rudolf Schreiter completed the sale of a collection of archaeological objects from the Calchaqui valleys to the Imperial Royal Natural History Court Museum of Vienna (at present Weltmuseum Wien). The transaction included the sending of a catalog, photographs and a manuscript in German describing the archaeological field work conducted in 1907. The manuscript remained unpublished until today; this essay is an introduction to our Spanish translation of the manuscript. We present an overview of the history of the formation of different collections gathered by Schreiter in the Calchaqui valleys, currently stored in museums in Argentina and Europe. This review allows us to assess the scale of Schreiter transactions and to know the strategies and ties through which he managed the acquisition and sale of large archeological collections over more than three decades.
\end{abstract}

Keywords: Archaeological collections; Museums; Northwest Argentina; Calchaqui valleys; documentary support of collections; Schreiter.

Introducción. De cómo llegó el manuscrito a nuestras manos. La traducción, la importancia de su difusión y de su puesta en contexto

Hace unos años, en el marco de nuestras indagaciones sobre la arqueología de los Valles Calchaquíes y el estudio de colecciones de museos, conocimos los trabajos de Etta Becker-Donner (1950, 1952, 1953)' , sobre las colecciones

\footnotetext{
${ }^{1}$ Etta Becker-Donner, etnóloga y lingüista austríaca, se desempeñó
} como investigadora, encargada de las colecciones de arqueología arqueológicas del Noroeste Argentino del Museo de Etnología de Viena ${ }^{2}$. Se trata de las colecciones Schuel y Schreiter, que fueron compradas a comienzos del siglo XX por el museo. Esta última se compone de 627 ítems arqueológicos provenientes de los valles de Santa María o Yocavil y del Cajón. Como condición para la adquisición, el museo solicitó la entrega de información de campo respaldatoria de las situaciones de hallazgo, necesaria

sudamericana y, a partir de 1955, como directora del Museo de Etnología de Viena.

${ }^{2}$ Actualmente Museo del Mundo de Viena (Weltmuseum Wien). 
para justificar su valor científico. Así fue que Schreiter remitió en 1912 una serie de fotografías, un catálogo y un informe manuscrito en alemán titulado "Beitrag zu den Ausgrabungen in den Calchaqui-Tälern" ("Artículo sobre las excavaciones en los Valles Calchaquíes") ${ }^{3}$.

En 2007 establecimos contacto con el Museo del Mundo de Viena y, gracias a las gestiones de la Dra. Claudia Augustat, Directora de la Colección de Sudamérica, llegó a nuestras manos una copia en papel de la transcripción mecanografiada del manuscrito inédito, junto con sus ilustraciones ${ }^{4}$. En este trabajo nos proponemos realizar una introducción a nuestra traducción al castellano del manuscrito, en el cual se relata una expedición arqueológica realizada en los valles de Santa María y del Cajón en 1907, relato que es ilustrado con gran cantidad de dibujos que reproducimos. El manuscrito, en su sencillez, contiene datos arqueológicos de interés, con observaciones de primera mano, en especial sobre aspectos funerarios. Algunos tipos de tumbas, como las tumbas bajo alero son mencionadas e ilustradas en este reporte. Esta clase de estructura funeraria positiva fue sistemáticamente explotada, al punto de que la mayoría de las que se han reportado en el valle han sufrido profanación o saqueo. En este contexto la información provista por Schreiter sobre este tipo de tumbas cobra especial interés.

El documento está organizado según un criterio geográfico, de acuerdo a los valles visitados y siguiendo el recorrido del río Cajón/Santa María. Primeramente se detallan las excavaciones realizadas en el valle del Cajón (Barranca Azul, El Fraile, El Río, Famabalasto) y luego las del valle de Santa María (Andalhuala, El Puesto, Fuerte Quemado, Amaicha, Salas, Moyeyacú, Yayamayo, Tiopunco, Quilmes). De cada localidad arqueológica se describe brevemente su ubicación y características del paisaje. Fundamentalmente se hace referencia a contextos funerarios, con detalles del tipo de sepultura, la cantidad de esqueletos con su correspondiente ubicación, orientación y estado de preservación y el acompañamiento funerario. Junto a las descripciones

\footnotetext{
${ }^{3}$ Becker-Donner cita a este informe como "Über die Gräber in dem Calchaquital in Nordargentinien". La copia mecanografiada que nos fuera remitida desde Viena dice en su carátula: "Abschrift eines Manuskriptes über die Gräber in dem Calchaqui Tal in Nord Argentinien"

${ }^{4}$ La transcripción mecanografiada consta de 26 páginas. A diferencia del resto, la copia de la carátula está manuscrita en tinta. En el texto, con la misma caligrafía que la de la carátula, se observan algunas correcciones ortográficas y agregados de palabras. En esta transcripción mecanografiada fueron intercaladas las ilustraciones del manuscrito original, en muchos casos, acompañadas por las anotaciones escritas de puño y letra por R. Schreiter. En la traducción respetamos las divisiones, sangrías, párrafos, frases en mayúsculas y subrayados de la transcripción. Optamos por conservar la escritura original de los topónimos, indicando en nota al pie el nombre correcto cuando encontramos discrepancias. Tradujimos también al castellano el texto manuscrito que acompaña a las ilustraciones, utilizando una tipografía cursiva con una fuente similar a la caligrafía original. Asimismo se mantuvo la relación de tamaño de las figuras de acuerdo con la copia mecanografiada.
}

hay ilustraciones esquemáticas de los entierros y de los distintos objetos encontrados. Además de los sitios funerarios se brinda información sobre otra clase de instalaciones habitacionales y agrícolas, entre las cuales resulta de interés la descripción y el croquis de una triple represa y de un grupo de cisternas en Fuerte Quemado.

Las primeras referencias publicadas de la colección y del manuscrito las encontramos en informes institucionales (Steindachner 1910-1911, 1912) y en un trabajo breve de Franz Heger, gestor de la adquisición, en el que describe cinco aríbalos o aribaloides que integran la colección (Heger 1913). Otra mención, ya en el ámbito nacional, la encontramos en un recordatorio publicado a 13 años del fallecimiento de Schreiter por Carlos Reyes M. Gajardo (1955). Allí repara en el, por entonces, novedoso trabajo de Becker-Donner de 1953 y destaca la relevancia del manuscrito en dicha obra:

\begin{abstract}
"Así cabe consignar, con particular interés, que uno de sus manuscritos conservado en el Museo de Göteborg (Suecia), ha sido objeto de un serio estudio por parte de Etta Becker-Donner, quien ha publicado un trabajo en Archiv für Völkerkunde Band VIII, 1953) intitulado "Los objetos no cerámicos de yacimientos del N. O. argentino", en donde analiza los textiles, la elaboración de madera, de hueso, metales y de piedra, en las páginas 273-324 de la mencionada revista. En todo el estudio mencionado, con mucho elogio, utiliza la información valiosa del manuscrito de Schreiter de 1912, sobre "Yacimientos calchaquíes en el N. O. argentino". (Reyes M. Gajardo 1955:16)5.
\end{abstract}

En paralelo a la realización de la traducción y para colocar en un contexto mayor al manuscrito y a la colección del Museo del Mundo de Viena, comenzamos a buscar referencias sobre otras colecciones arqueológicas reunidas y comercializadas por Schreiter a museos y particulares, con el fin de comprender la escala de sus adquisiciones de objetos arqueológicos. En este proceso de indagación fue creciendo nuestra curiosidad por la figura de Rudolf Schreiter, su biografía, su desempeño en el campo científico, en particular su obra arqueológica y el contexto en el cual se desenvolvió como coleccionista y comerciante de antigüedades. Sobre estos últimos aspectos comenta Reyes M. Gajardo:

“Estas expediciones por diversas regiones del noroeste le permitieron ser no sólo un gran conocedor de estas zonas, sino también el que aprovechara de las excursiones para completar las colecciones botánicas y entomológicas, figurando en su haber más de 7 mil números de

\footnotetext{
5 Reyes M. Gajardo confunde el museo en el cual se conserva el manuscrito. Es posible que esta confusión se relacione con la existencia de una colección Schreiter en el Museo de Gotemburgo.
} 
especies botánicas con cerca de 35 mil ejemplares de herbario; y con unos 10 mil números de insectos; como también sus adquisiciones arqueológicas in situ, que ascienden a cerca de 3 mil piezas." (Reyes M. Gajardo 1955:16, destacado nuestro).

A partir de la bibliografía recopilamos información sobre la existencia de colecciones reunidas, donadas o vendidas por Schreiter a museos en Leipzig, Berlín, Viena, Gotemburgo, Tucumán y Buenos Aires y también a coleccionistas particulares. Con base en datos publicados, comunicaciones personales con encargados de diferentes áreas de los museos y consultas de material de archivo pudimos conocer aspectos de las historias de cada colección e, inclusive, identificamos una colección que había sido colocada en el ámbito privado y de la que, hasta el momento, se desconocía la gestión de Schreiter en su conformación (Col. Breyer, Museo Etnográfico "Juan B. Ambrosetti" -MEJBA-). También nos interiorizamos en su obra édita en el campo de la arqueología (Schreiter 1919, 1928, 1934, 1936a, 1936b), caracterizada por escritos breves y descriptivos, con una documentación visual importante; mapas, croquis de contextos funerarios, buenas ilustraciones y fotografías de objetos.

Diversas preguntas comenzaron entonces a surgir. ¿De qué maneras obtenía las piezas que comerciaba? ¿Cuál había sido la magnitud de sus excavaciones y sus redes de relaciones (Farro 2009; Podgorny 2004) para lograr la adquisición de objetos y las ventas de colecciones? ¿Cuál era su relación con arqueólogos y comerciantes de antigüedades contemporáneos? Nuestro interés en Rudolf Schreiter tiene que ver principalmente con la comprensión de la integración en su persona de las facetas de autodidacta - experto, inserto en los esquemas institucionales para el desempeño científico en Tucumán, junto con la de coleccionista y comerciante de piezas arqueológicas.

A continuación haremos una breve mención a aspectos de su biografía y obra arqueológica para luego avanzar sobre consideraciones respecto a las actividades de Schreiter como comerciante de colecciones de antigüedades.

\section{Algunos hitos biográficos y de la obra de Schreiter}

Karl Rudolf Schreiter ${ }^{6}$ nació el 13 de agosto de 1877 en Chemnitz, Sajonia. Séptimo de ocho hermanos finalizó sus estudios primarios y secundarios en dicha ciudad. Su padre fue tejedor y, más tarde, fabricante de telas para tapicería; dos de sus hermanos siguieron los pasos del padre mientras que Rudolf trabajó en una firma de artículos electrotécnicos. Su madre, quien recibió una educación campesina, le habría transmitido su interés por

\footnotetext{
6 En diferentes publicaciones su nombre varía (Rudolf, Rodolfo, Rodolphe, Carlos Rodolfo), de acuerdo con la costumbre de adecuar los nombres al idioma del lugar o de la edición.
}

la naturaleza. Se desconoce con exactitud cuándo llegó a la Argentina, probablemente entre 1901 y 1902, durante la segunda presidencia de Roca. Para esa época, junto a su esposa, Julia Sofía Löffler, se instaló en la provincia de Tucumán desempeñándose inicialmente como comerciante (Amenta 2008:14-16; Obituario Revista de la Sociedad Entomológica Argentina 1943: 56-57).

Entre sus intereses científicos se destacaron la botánica, la entomología y la arqueología, áreas en las que se desarrolló como autodidacta, produciendo varias publicaciones, trabajos inéditos y apuntes dispersos y entablando relaciones con especialistas del medio nacional e internacional. En los años que residió en Tucumán Schreiter realizó diversos viajes de estudio con el objetivo de recolectar material botánico, entomológico y arqueológico para su posterior organización y catalogación en colecciones. Algunos de estos viajes fueron organizados de modo privado, mientras que otros se realizaron en el marco institucional del Museo de Historia Natural - Instituto de Etnología - Museo Miguel Lillo, donde se desempeñó desde 1915 hasta su muerte en 1942.

Sus vínculos con investigadores naturalistas en la Argentina y en el extranjero incluyeron el intercambio y venta de especímenes de plantas, insectos, rocas y objetos arqueológicos, y también diversas consultas recíprocas. Por ejemplo, intercambiaba ejemplares de insectos con el entomólogo del Museo de La Plata Carlos Bruch. Con el Dr. Vignati, antropólogo del mismo museo, mantuvo correspondencia acerca de su interpretación sobre la funcionalidad de los morteros. Efectuaba consultas sobre especies botánicas con Alberto Castellanos del Museo Nacional de Historia Natural de Buenos Aires e intercambiaba información y especies de herbario con distintos investigadores, particularmente del Chaco, entre ellos Augusto Schulz y Teodoro Meyer. A nivel internacional, mantenía contactos con los Amigos del Museo de Historia Natural de Chicago. Los científicos de la Estación Experimental Agrícola de Tucumán le solicitaban información sobre la conservación de insectos. También asesoraba a investigadores, como el entomólogo Juan M. Bosq y el ingeniero agrónomo Lorenzo Parodi, sobre itinerarios de viajes, tiempos de recorrido y equipamiento ${ }^{7}$.

La primera de sus expediciones a los valles Calchaquíes para la adquisición de objetos arqueológicos de la que tenemos noticia fue realizada a mediados de 1905, no obstante resulta plausible que haya realizado viajes previos $^{8}$. En 1906 también recorre los valles excavando lo que él mismo consideró una pequeña parte del valle de Santa María que incluía las zonas de Santa María, desde Quilmes hasta Colalao y de Amaicha hasta Tafí. El

\footnotetext{
${ }^{7}$ Según epistolario publicado por Amenta (2008), cartas 54, 146, 174, $176,214,221$.

8 Sabemos que viajó al valle de Tafí en 1904, fecha que coloca en el epígrafe de una fotografía (Schreiter 1928, Lámina XVII).
} 
éxito en las búsquedas lo llevó a planificar otro viaje en octubre de 1907, del cual da cuenta el manuscrito de 1912. Estos viajes serían los antecedentes de numerosos viajes posteriores e inaugurarían su faceta de comerciante de antigüedades.

Al término de las sesiones del XVI Congreso Internacional de Americanistas realizadas entre el 17 y el 24 de mayo de 1910 en la ciudad de Buenos Aires se realizó una gran excursión que recorrió parte del noroeste argentino, Bolivia y Perú. La delegación de científicos permaneció en Tucumán por un día, donde fue recibida por Rudolf Schreiter, quien ofició como guía en un paseo al pie de los cerros ubicados hacia el occidente de la ciudad (Steindachner 1910-1911: 56). Su participación en este evento muestra que, ya por entonces, Schreiter poseía contactos e intereses comunes con la comunidad científica en el país.

En 1914 es convocado por el naturalista Miguel Lillo para trabajar en la organización de sus colecciones de reptiles e insectos. Cuando en diciembre de 1915 se fundó el Museo Provincial de Historia Natural, Miguel Lillo fue designado Director Honorario y nombró a Schreiter como conservador. Al año siguiente, en el marco de los festejos por el centenario de la Independencia, se celebró en la ciudad de Tucumán la Primera Reunión Nacional de la Sociedad Argentina de Ciencias Naturales, en la que Schreiter participó como vocal junto al Sr. Inocencio Liberani, entre otros ${ }^{9}$. Asimismo, se encargó de la exhibición de las piezas de una reciente campaña en los valles de Santa María, El Cajón y Hualfín que realizó entre octubre y diciembre de 1915 (Carrizo 2006:201). De ese modo Schreiter se vincula con el grupo de intelectuales de la elite tucumana conocido como "Generación del centenario" o "Generación de la Universidad" integrado por personalidades influyentes del campo cultural, económico y político como Miguel Lillo, Ernesto Padilla, Juan B. Terán, Alberto Rougés, José Graciano Sortheix, José Ignacio Aráoz, Juan Heller, José Padilla y Alfredo Guzmán, entre otros (Arenas 1998; Peña de Bascary 2014).

Por gestiones de Juan B. Terán ${ }^{10}$ queda encargado desde 1919 también de la sección del Jardín Botánico en el "Parque 9 de Julio"11. Ese año realiza un viaje a Buenos Aires en el cual toma contacto con diferentes personalidades de la arqueología; así visitó a Salvador Debenedetti, por entonces director del Museo Etnográfico de la Universidad de Buenos Aires y a Eric Boman, por entonces Jefe de la Sección Arqueología en el Museo Nacional de Historia Natural "Bernardino Rivadavia". Con este último se consolida una relación epistolar que se mantiene hasta su muerte en $1924^{12}$. Schreiter acepta

\footnotetext{
${ }^{9}$ En la reunión se consideró el proyecto de reglamentación de la ley nacional sobre yacimientos arqueológicos. Se nombró una comisión, constituida por los directores de los museos de Historia Natural de Buenos Aires y de La Plata y del Museo Etnográfico de la UBA (Primera Reunión Nacional de la Sociedad Argentina de Ciencias 1919, pp. 539).

${ }^{10}$ Por entonces rector de la Universidad de Tucumán.

11 Carta de Schreiter a Boman 2/6/1923 en Archivo Fotográfico y Documental MEJBA.

12 Schreiter forma parte de la comisión de homenaje y reúne dinero
}

con entusiasmo el ofrecimiento de Boman de asistirlo en sus primeras publicaciones sobre temas arqueológicos. Es así como ese mismo año, y contando con su valioso asesoramiento, dio a conocer en una revista científica alemana de Buenos Aires el artículo Distintas clases de sepulturas antiguas observadas en los valles Calchaquíes, con una Introducción del propio Boman (Schreiter 1919). En el Archivo Fotográfico y Documental del Museo Etnográfico se conserva parte del epistolario entre ambos desde julio de 1919 hasta septiembre de 1924. Estos documentos permiten conocer el importante papel tutorial del arqueólogo sueco, aconsejando aspectos del contenido, estructura y edición del trabajo mencionado con el fin de que realice una exposición sistemática de sus observaciones $^{13}$. A través de estas misivas se desarrolló un vínculo de afecto y respeto que se sostuvo a través de mutuas consultas e intercambio de bibliografía y objetos arqueológicos. Así Boman menciona en diferentes trabajos información inédita sobre hallazgos en contextos funerarios facilitada por Schreiter (Boman 1920: 537; 1923: 19, 23-24) que le sirven a sus argumentos respecto de la diacronización en la región Diaguita ${ }^{14}$.

A lo largo de la década de 1920 participó de diversas expediciones científicas ${ }^{15}$. En 1920, realizó una gira por las Sierras de Tucumán en calidad de ayudante del geógrafo Dr. Franz Kühn, profesor del Instituto Nacional del Profesorado Secundario (Kühn y Rohmeder 1943:11; Weiser 1920:98). En 1922, producto de una expedición en Amaicha y Quilmes, confeccionó un mapa a mano de la región que se conserva en el Archivo Padilla, Archivo Histórico de Tucumán (Amenta 2008:29) ${ }^{16}$. Entre 1924 y 1925 viajó a Tartagal, tras lo cual publicó Informe sobre una excursión a Tartagal en el Boletín del Museo de Historia Natural de la Universidad Nacional de Tucumán, la primera de una serie de cinco publicaciones sobre entomología entre 1925 y 1930 (Obituario Revista de la Sociedad Entomológica Argentina 1943: 56-57).

En 1928 publicó Monumentos megalíticos y pictográficos en los altivalles de la provincia de Tucumán en el Boletín del Museo de Historia Natural, su segunda publicación sobre temas arqueológicos. Se trata de una obra postergada, sobre la cual se refirió en la correspondencia

entre las amistades en Tucumán para el mausoleo de Boman en el Cementerio Alemán de Buenos Aires (Amenta 2008:30)

13 Parecería que las observaciones realizadas por Schreiter en este trabajo tienen que ver con una expedición realizada entre septiembre y diciembre de 1915, aunque el manuscrito traducido revela algunas coincidencias que indican observaciones derivadas del viaje de 1907.

${ }^{14}$ En diferentes cartas Boman consulta a Schreiter sobre sus hallazgos de Aggry-Perlen. Schreiter remite a Boman algunas perlas y otros objetos arqueológicos (Cartas Schreiter a Boman, 7/1/1920; 26/1/1920; 28/1/1920; 20/10/1920; 29/10/1920; 4/2/1922, en Archivo Fotográfico y Documental MEJBA).

15 En 1925 el Museo de Historia Natural pasó a depender de la Universidad Nacional de Tucumán y se nombró a Schreiter como jefe de Sección. Esta Sección sería el germen del Instituto de Etnología organizado y dirigido formalmente por Alfred Métraux durante el período de 1928 a 1934. En 1933, a dos años de la muerte de Lillo, el Museo contaba con cuatro Secciones (Arqueología, Mineralogía, Botánica y Zoología) y Schreiter tenía los cargos de Encargado y Conservador del Museo (Amenta 2008: 17-20).

${ }^{16}$ Dicho mapa se relaciona con el trabajo Investigación Arqueológica en la región de Amaicha y Quilmes de 1932 (Amenta 2008:33). No encontramos referencias que indiquen que se trata de una publicación. 
con Boman. El texto es breve, acompañado por fotografías y dos mapas de Santa María y Tafí. Estos mapas son interesantes, ya que sitúa los menhires y petroglifos y ubica sitios poco conocidos de los cuales proceden varios objetos de la colección vendida a Viena (ej. Kishka, Utula, Chuspiyacu, etc.).

En 1930 comenzó sus excavaciones en La Candelaria. La primera expedición fue realizada por el Instituto de Etnología. Alfred Métraux, por entonces director del Instituto, y Schreiter encabezaron la partida (Métraux 1930: 402). Luego realizó otros viajes por cuenta propia conformando una colección personal con los materiales obtenidos. En 1934 Schreiter publica La civilisation de La Candelaria et son extensión Dans la Province de Tucumán, traducido al francés por Métraux. El texto inicia con referencias a la flora y la fauna y menciona información histórica acerca de los Tonocoté. Se describen entierros y sus asociaciones materiales. A partir de esta publicación cuenta con las excelentes ilustraciones de Silvio Giménez, miembro del instituto. Muchas de las piezas arqueológicas recuperadas integran la colección vendida al Museo Argentino de Ciencias Naturales "Bernardino Rivadavia".

Schreiter fue un colaborador muy cercano en aspectos administrativos y académicos de la gestión de Métraux en el Instituto. Entre 1934 y 1937, tras la renuncia de Métraux, ocupó de modo interino y a pesar de no poseer un perfil académico, el puesto de director del Instituto de Etnología (Arenas y Taboada 2010; Carrizo 2004). Durante este período realizó excavaciones en el marco de expediciones oficiales del Instituto en el Departamento de Belén, Catamarca. Como resultado publica Nota preliminar sobre una exploración arqueológica en la Loma de La Florida. Corral Quemado, Departamento de Belén (Catamarca) (Schreiter 1936a). Este trabajo muestra una maduración importante del autor en cuanto a estructura del texto y metodología de campo. Comienza planteando dos temas de discusión: la antigüedad y origen de la alfarería "draconiana" y lo apropiado o no de las diferentes denominaciones que se le han impuesto: "draconiana" o "alfarería de los barreales", cuando lo representado son felinos. Realiza una descripción de la estratificación de los sedimentos en la zona y ubica las clases de tumbas y hallazgos en los estratos. Descubre que la alfarería draconiana se halla a profundidades mayores que la polícroma, dato que le permite concluir que en La Florida existen dos niveles culturales con enterratorios superpuestos y ubicados a distintas profundidades. Destaca que en ninguna de las excavaciones realizadas en la Loma de La Florida se ha comprobado una mezcla de ajuares de ambos niveles. Este énfasis en la estratigrafía y en la diacronización sobresale en un momento en el cual la temática no era frecuentada entre otros arqueólogos locales.

También en 1936 publica Enterratorios indígenas en las grutas de Villavil. Departamento de Belén (Catamarca) (Schreiter 1936b). Es un artículo breve que presenta una serie de enterratorios bajo peñascos, hallados en Villavil.
Se destaca nuevamente su interés por la diacronización de las tumbas y aparece también el tema de las interacciones regionales: la presencia de conchas del Pacífico como evidencia de intercambio con pueblos de la costa.

En 1937, con el nombramiento del Dr. Enrique Palavecino como nuevo Director General del Museo de Historia Natural y del Instituto de Etnología se produjeron cambios en la estructura del museo, entre ellos, el traslado a una nueva sede, la creación de nuevas Secciones y la elaboración de un nuevo reglamento. En este nuevo contexto Schreiter fue reasignado al cargo de jefe de la Sección de Zoología. Algunos de estos cambios le disgustaron; a juzgar por comentarios recogidos del epistolario de Schreiter, su relación con el nuevo director fue conflictiva (Amenta 2008:23-28; Peña de Bascary 2014:9).

Aparentemente una de las cuestiones del nuevo reglamento que molestó a Schreiter, y que nos interesa destacar dada la temática de nuestras indagaciones, fue la explícita prohibición a los empleados del museo de reunir colecciones particulares con objetos arqueológicos. En este sentido, Palavecino estaba al tanto de que Schreiter poseía una colección arqueológica personal en continuo incremento y de sus antecedentes en la comercialización de material arqueológico; los cambios en la normativa afectaban entonces de modo directo los intereses de Schreiter. Esta nueva situación derivó en comentarios que trascendieron el ámbito institucional alcanzando la esfera política provincial, tal como se puede apreciar en el intercambio de correspondencia sobre este tema. Por ejemplo, el Dr. Rougés, miembro de la Fundación Lillo, en una carta a Padilla, ex-gobernador de Tucumán, sostiene que, como la Universidad no se había ocupado de la arqueología en los primeros 20 años del museo:

"...los yacimientos son destrozados, más que explotados, por particulares ignorantes, de tal manera que es de felicitarse que alguien haga inteligentemente una colección, que don Rodolfo está dispuesto a entregar por el costo" (Carta de Rougés a Padilla, sin fecha en Amenta 2008: 26).

Asimismo, en relación a las diferentes compras de objetos arqueológicos de oro y plata en joyerías realizadas por Schreiter, la respuesta del ex-gobernador Padilla al Dr. Rougés es condescendiente:

“... en realidad, la Universidad no quiso hacer nada ni se interesó por buscar ni adquirir colecciones; no puede objetarse a don Rodolfo que la ha conseguido con su trabajo propio" (Carta de Padilla a Rougés, sin fecha en Amenta 2008: 26).

En 1938, luego de la reorganización de los institutos del Museo de Historia Natural, Schreiter pasó a dirigir el Instituto Miguel Lillo de la Universidad Nacional de Tucumán, dedicado a la investigación botánica. Tras la 
desvinculación de Palavecino conduce por un tiempo corto el Instituto de Etnología hasta la designación de Radamés Altieri como director a mediados de 1938. Aceptó además el cargo como Director ad honorem del Instituto de Zoología hasta 1942, año en que muere (Amenta 2008:27; Carrizo 2010:243).

\section{Las colecciones Schreiter en el mundo. Consideraciones sobre las actividades de Schreiter como colector y comerciante de piezas}

La breve reseña anterior nos permite observar que Schreiter se dedicó, entre otras actividades, a la conformación de colecciones arqueológicas durante más de tres décadas, a lo largo de las cuales alternó viajes de exploración particulares e institucionales. Una manera de mensurar su actividad como coleccionista y comerciante de antigüedades es conocer la historia de la conformación y características de las colecciones que donó o vendió a museos y particulares. Para ello trabajamos en la búsqueda de bibliografía, contactamos al personal de museos y consultamos material de archivo. Las historias reconstruidas, que exponemos a continuación de acuerdo a un orden cronológico, constituyen sólo un conocimiento inicial sobre cada una.

\section{La colección en Leipzig}

La colección Schreiter, adquirida en 1907 por el Museo Grassi de Etnología en Leipzig (Grassi Museum für Völkerkunde zu Leipzig), es, al parecer, la primera venta privada que hace Schreiter a un museo en Europa. Originalmente contenía 612 entradas de objetos arqueológicos, etnográficos y también "turísticos" procedentes del valle Calchaquí; durante la Segunda Guerra Mundial se destruyeron 332 ítems inventariados (actualmente la conforman 280 ítems).

De acuerdo a los documentos de la adquisición (1907/51), las tratativas para la venta duraron dos años y se efectuaron por correspondencia entre Schreiter y el museo, a través del Profesor Karl Weule, su director. Asimismo, según las cartas depositadas en el archivo del Museo, hubo comunicación entre Weule y un hermano de Schreiter, Emil, que vivía en Chemnitz; dicha correspondencia es de carácter informal lo que permite pensar que Schreiter se vinculó con el Museo a través de la relación personal de su hermano con el director. Más aún, de acuerdo a una carta de Emil Schreiter dirigida a la esposa de Weule, también vinculada con la adquisición de la colección, es probable que los Schreiter hayan tenido algún vínculo familiar con el profesor.

Según los resúmenes de correspondencia que pudimos consultar, una vez hecho el contacto con Weule, Schreiter se compromete a reservarle al Museo todas las piezas que poseía del valle Calchaquí. A mediados de 1905 emprende una "pequeña" expedición para ampliar la colección, para la que solicita un adelanto de dinero al Museo Grassi. El recorrido comenzó en Tafí, duró aproximadamente un mes y logró llenar 12 cajones de piezas arqueológicas.
Schreiter consideró esta expedición como un trabajo preliminar a un viaje mayor a realizar en el futuro. En estas misivas menciona varias veces a Manuel Zavaleta, quien aparentemente en esa época tenía un encargo importante de objetos arqueológicos del valle Calchaquí para el Museo de Berlín, advirtiendo a Weule de no involucrarse con él (Christine Seige, comunicación personal 2010).

Las respuestas del museo se hacen esperar, cuestión que inquieta a Schreiter, quien a través de diferentes cartas intenta agilizar la operación. Se infiere que habría escaso interés por adquirir materiales de Calchaquí, cosa que él intenta modificar a través de la correspondencia.

Finalmente, la colección se vendió en 1907 en 15.000 marcos, de los cuales 11.000 fueron pagados por un patrocinador del Museo, el Dr. Herrmann Meyer, en tres cuotas de 5.000, 2.500 y 2.500 marcos respectivamente ${ }^{17}$ y los 4.000 marcos restantes fueron abonados por el Museo, a los que se descontaron 465,70 marcos como equivalente al valor de restauración de las piezas cerámicas rotas durante su traslado. Junto a la colección de objetos, se adjuntó un diario de viaje de aproximadamente 15 páginas, un inventario manuscrito de las piezas con procedencias y un croquis de la expedición ${ }^{18}$. La compra se comunica en el Libro Anual del Museo (Jahrbuch des Museums für Völkerkunde zu Leipzig 1907:22).

\section{La colección en Berlín}

A mediados de 1908, por correspondencia desde Chemnitz, Schreiter ofrece una colección al Museo Real de Etnología (Königliches Museum für Völkerkunde) en Berlín, contactando directamente a su director, el mesoamericanista Profesor Eduard Seler. Si bien, en un primer momento, el Museo de Historia Natural de Viena, a través de su director Franz Heger, tendría interés en algunas de las piezas, finalmente Schreiter envía a Berlín los 33 objetos (de acuerdo a inventario) que componen la colección para mostrarla al Comité de Evaluación del Museo. A esto siguieron las tratativas por el precio de la colección; Schreiter la ofrece por 3000 marcos pero el Comité se muestra reticente a pagar dicha cifra considerando que el año anterior le había comprado a Zavaleta una colección de piezas del Valle Calchaquí. Finalmente, el precio pagado fue de 1000 marcos (Manuela Fischer, comunicación personal 2011).

En este museo existe asimismo una colección denominada Wilhelm Herrmann - Rud. Schreiter (donantes), integrada por 114 elementos. Si bien aún no obtuvimos información sobre la misma, es factible que se trate de una colección adquirida por Herrmann a Schreiter entre 1905-1906. En la correspondencia del 28/1/1905 al Profesor Karl Weule, del museo de Leipzig, Schreiter comenta que en ese año, un tal Sr. Herrmann del Berliner Paläontologisches Museum iría a una gran excursión por el valle Calchaquí y

\footnotetext{
${ }_{17}$ De los 1.000 marcos que faltan no hay mención en las actas.

${ }^{18}$ Documento 1907/51, Archivo Museo Grassi.
} 
que "esta misma persona, hace dos años viajó por aquí con una gran colección de Bolivia"19. Este dato, sumado al nombre compuesto de la colección, nos permite hipotetizar que Schreiter fue el colector.

\section{La colección en Viena}

En el Museo del Mundo de Viena se encuentra la colección de Schreiter de la que procede el Manuscrito que hemos traducido; ésta fue adquirida en dos partidas, en los años 1910 y 1912 respectivamente. En el primer lote (Post 16/1910) se compraron 62 objetos a través de Franz Heger, concejero gubernamental ("Regierungsrat") del, en ese entonces, Museo de la corte real imperial de historia natural (K.K. Naturhistorische Hofmuseum), por el precio de 700 pesos moneda nacional, o sea, 1736 coronas. Es de destacar que Heger viajaba frecuentemente a Sudamérica para realizar compras directas, lo que constituía una práctica corriente para la institución (Claudia Augustat, comunicación personal 2010). La compra se efectuó en Tucumán durante el viaje de Heger por Sudamérica en el marco del XVI Congreso Internacional de Americanistas que sesionó en Buenos Aires. Probablemente el contacto entre ambos se estableció cuando, en ocasión del viaje post - congreso, Schreiter realiza una excursión guiada para la comitiva de congresistas a las montañas aledañas de la ciudad (Steindachner 1910-1911:53-57).

Las piezas que conforman el lote Post $16 / 1910$ son producto de excavaciones realizadas por Schreiter en el valle de Santa María entre 1909 y 1910 (Claudia Augustat, comunicación personal 2010) y fueron recogidas en Tucumán por Heger a la vuelta del viaje post - congreso, tal como lo refiere en una carta a Boman:

"Aggryperlen; Lamento infinitamente no poderle servir con los datos que Ud. desea tener sobre esta clase de perlas. El sr. Franz Heger me visitó en 1910 y vió la pequeña colección particular mia que conservaba en mi casa. Esta colección se la llevó despues de su regreso de Bolivia." (Carta a Boman, 7 de enero de 1920, Archivo Fotográfico y Documental MEJBA).

La segunda partida (Post 8/1912), también comprada por Heger, contiene 565 objetos por los que se pagaron 12.500 marcos, o sea, 14.707 coronas (Claudia Augustat, comunicación personal 2010). Dicho lote se encontraba depositado en Chemnitz desde 1908 y fue Heger, con la asistencia de los hermanos de Schreiter, Alfred y Emil, quien se encargó personalmente de su traslado hasta Viena entre agosto y septiembre de 1911 (Heger 1913; Steindachner 1912: 4, 53).

En palabras de Heger:

“En el año 1910 adquirí del Sr. Rudolf Schreiter,

19 Carta de Schreiter a Weule 28 de enero 1905, en Documento 1907/51, Archivo Museo Grassi, traducción propia. un alemán instalado desde hace largos años en Tucumán, una pequeña colección de antigüedades que él mismo había excavado poco antes en el valle del río Santa María. En septiembre del año pasado tuve la fortuna de adquirir del mismo Señor una gran colección de antigüedades de la cultura Diaguita para el k. k. naturhist. Hofmuseum en Viena (Museo de Historia Natural de Viena), la que había excavado en los años 1907 y 1908 en las excursiones a diversos puntos de este valle, el cual desde el sur fluye hacia el valle Calchaquí. Él llevó esta vasta colección a Chemnitz, su ciudad natal en Sajonia, en el verano de 1908, donde permaneció depositada por varios años. Debo al Sr. Schreiter un número de registros fotográficos, que él mismo había tomado en estas excursiones, así como un pequeño manuscrito, en el que comenta los lugares de hallazgo más importantes." (Heger 1913: 293, traducción propia).

Con respecto al precio pagado por el segundo lote, en los Anales del Museo, se menciona:

“...Esta excelente colección, depositada en Chemnitz desde el año 1908, fue adquirida a un precio relativamente bajo, gracias a la devoción del coleccionista" (Steindachner 1912:4, traducción propia).

En su búsqueda por valorar el potencial de la colección Schreiter para la investigación arqueológica Etta BeckerDonner realizó un cotejo entre el manuscrito en cuestión, los datos del catálogo y los objetos, lo que la llevó a notar problemas. Entre ellos, menciona que las considerables tareas de campo reseñadas en el informe casi nunca se refieren a los objetos de la colección. Las descripciones son poco claras, de modo que las piezas raramente pueden identificarse. Asimismo, en el listado de la colección se identifica a algunas piezas con procedencias que incluyen un grupo de localidades, de modo que no se puede resolver su origen (Becker-Donner 1950: 2, 70).

A pesar de estos inconvenientes, Becker-Donner aprovecha los datos relevantes del manuscrito realizando una breve síntesis, publica también dos fotografías de Fuerte Quemado y pasa a tinta siete de sus ilustraciones. También elabora un mapa del valle de Santa María y alrededores, donde figuran las localidades comprendidas en el catálogo (Becker-Donner 1950: 64-80). Su trabajo constituye un catálogo descriptivo exhaustivo y con ilustraciones de toda la colección. Adecua la descripción a las tipologías del momento, propone agrupamientos novedosos y realiza análisis tecnológicos de los materiales y sugerentes interpretaciones.

\section{La colección en Gotemburgo}

La colección fue comprada en 1930 por el Museo de 
Gotemburgo (Göteborgs Museum), cuando Erland Nördenskiöld era su director, y consta de 397 entradas. De acuerdo a la correspondencia relativa a su adquisición conservada en el archivo del Museo, Schreiter deseaba vender su colección y Alfred Métraux, quien en este tiempo era director del Instituto de Etnología de Tucumán y era ex alumno de Erland Nördenskiöld, le sugiere la posibilidad de venderla a Gotemburgo, oficiando de mediador en la transacción. Para concretar la venta Schreiter completó un catálogo de la colección, con la mayoría de los objetos fotografiados y los remanentes dibujados. Dados los antecedentes de investigación suecos en el NOA, la necesidad del Museo de completar sus colecciones procedentes de Argentina y el interés por adquirir una colección con valor científico con información sobre los hallazgos, la compra fue bienvenida. Para su traslado a Gotemburgo, el consulado sueco mantuvo una posición de intermediario dado que el cónsul de Suecia fue quien recibió y despachó la colección por barco. Inmediatamente después de su llegada se organizó una exposición en el Museo. Con posterioridad a la recepción de la colección, continuó el intercambio epistolar solicitando información y fotografías. Schreiter intentó seguir vendiéndoles otras colecciones pero no fue posible debido a problemas económicos por parte del Museo y posiblemente por el pronto fallecimiento de Nördenskiöld (Isaccson 1999; Stenborg 1999).

Un catálogo de esta colección fue publicado en un número especial de Etnologiska Studier editado por Per Stenborg y Adriana Muñoz (1999). Lo acompañan una serie de artículos referidos a la arqueología calchaquí, la adquisición de la colección y estudios específicos de sus materiales, en la cual se destacan dos máscaras oriundas de Quilmes.

\section{Las colecciones en Buenos Aires}

\section{Intentos de venta al Museo Etnográfico}

Entre agosto y septiembre de 1919 Schreiter mantiene correspondencia con Salvador Debenedetti, por entonces director del Museo Etnográfico de la Universidad de Buenos Aires (actualmente Museo Etnográfico "Juan B. Ambrosetti" -MEJBA-), en la cual se hace referencia a la posibilidad de una venta de su colección de antigüedades de Amaicha, Fuerte Quemado y zona norte de la ciudad de Tucumán. En el archivo del museo se conservan tres misivas remitidas por Schreiter desde Tucumán, mas no las respuestas de Debenedetti. En estas cartas se da cuenta de una visita previa de Schreiter a Buenos Aires, del envío de fotografías, y se describen también los apremios económicos que lo llevan a ofrecer la venta. Transcribimos una de las misivas:

"Tucumán Setiembre 7 de 1919

Señor Dr. Salvador Debenedetti, Buenos Aires.
Muy estimado Doctor,

Hace aproximadamente 8 días que le hice otro envío de fotografías sobre piezas de mi colección calchaquí.

Suponiendo que ya estén en su poder las mencionadas fotografías me permito preguntarle si le fué posible de hacer algo ya en el asunto de la adquisición de dicha colección. Como ya le expliqué en mi visita en esa tengo que deshacerme de lo que tengo en colecciones por motivo de que no nos pagan los meses atrazados del año pasado y de este año y por eso tenía que liquidar una propiedad mia que me costó 15 años de trabajo -adios mi plata.- y tener colecciones de esa índole en casa alquilada es otro problema. En espera de su buena contestación saluda a Ud. muy afectuosamente s.s.s. Rodolfo Schreiter". (Carta en Archivo Fotográfico y Documental MEJBA).

Esta negociación aparentemente no alcanzó los resultados esperados, puesto que el museo no adquirió la colección ofrecida.

\section{Colección Schreiter}

La "Colección Schreiter" actualmente depositada en el Museo Etnográfico "Juan B. Ambrosetti" se conformó a partir de al menos tres ingresos de materiales entre compras y donaciones; aparentemente estos conjuntos formaron parte de una misma negociación iniciada en 1934 y concluida en 1936. La colección fue adquirida por el Museo Nacional de Historia Natural "Bernardino Rivadavia" y con posterioridad pasó al Museo Etnográfico cuando, en el año 1947 se realizó el traslado de las Secciones Arqueología, Etnografía y Antropología que involucró a las colecciones y al material de archivo.

En el Archivo Fotográfico y Documental y en el Área de Arqueología del Museo Etnográfico se conservan fragmentos de la correspondencia interna del Museo Nacional, catálogos e inventarios que permiten conocer algunos aspectos de la transacción. Un primer lote de 33 objetos, oriundos del valle de Santa María, Catamarca (números de catálogo 34-180 a 34-212) fue adquirido por compra por la suma de $\$ 200$ pesos moneda nacional. Luego hay una serie de 37 entradas de catálogo que corresponden a materiales donados por Schreiter con procedencias de La Candelaria, Salta; Corral Quemado, Catamarca y Río de la Hoyada, Tucumán. Así, el conjunto de las adquisiciones de 1934 suman, entre compra y donaciones, 70 entradas de catálogo. Ese mismo año avanzan las negociaciones para la venta de un gran lote de materiales, principalmente de La Candelaria. Eduardo Casanova, jefe de la Sección Arqueología, se encargó de examinar la propuesta, recomendando al director del museo, Martín Doello Jurado, la adquisición. 
"Museo, Junio 6 de 1934.

Señor Director:

He examinado el Catálogo de la colección ofrecida en venta por el señor don Rodolfo Schreiter y considero que su adquisición es de gran interés para este Museo, dado que la casi totalidad de las piezas proceden de La Candelaria (Salta) y son exponentes de una cultura que no está representada en nuestro museo ni en ninguno de los museos argentinos. Por las mismas circunstancias considero que no es excesivo el precio de $\$ 4.000$, especialmente teniendo en cuenta el cuidado con que se ha confeccionado el catálogo lo que hace presumir que en el terreno se ha procedido también con esmero, como igualmente lo prueban algunas fotografías que ilustran dicho catálogo. únicamente creo conveniente que al realizarse la operación se haga constar que además de los objetos el señor Schreiter entregará todas las fotografías y negativos referentes a la colección, así como libretas de viaje o apuntes con las observaciones registradas sobre el terreno, mapas, croquis, etc.

Saludo al señor director con mi mayor consideración: E. Casanova". (Carta en Archivo Fotográfico y Documental MEJBA).

Es sugerente que en el año 1934 se publicara el artículo La civilisation de La Candelaria et son extensión Dans la Province de Tucumán. Resulta plausible que la difusión de esta obra en una publicación internacional, que daba cuenta de información arqueológica novedosa y que contaba con el aval de un antropólogo de prestigio internacional como Métraux, haya incidido favorablemente en la apreciación de la importancia de esta colección. Ésta ingresó al catálogo del Museo Nacional de Historia Natural en 1936. En su mayoría, los objetos proceden de diversos sitios en La Candelaria, provincia de Salta; hemos observado que algunos de los materiales ilustrados en el trabajo de Schreiter (1934) integran esta colección. También hay elementos procedentes de valles Calchaquíes, valle de Yocavil, valle del Cajón, Tafí, Choromoro, Toro Loco, La Ciénaga, Tapia y Vipos. En total suman 841 entradas que corresponden a alfarería, objetos de piedra, metal, hueso, cuentas, cestería, textil, óseo y caracol. Junto con los objetos se entregó un catálogo con descripciones, dibujos y fotografías. Se ofrece información sobre algunas asociaciones funerarias y fotografías de contextos en La Candelaria (Figura 1).

\section{Colección Breyer}

Hemos podido articular evidencias documentales independientes que testimonian que esta importante colección contiene materiales reunidos por Schreiter. La colección, junto con parte de la documentación referente a su adquisición y fichas de catálogo, ingresó también al Museo Etnográfico en 1947, junto con las restantes colecciones del Museo Nacional de Historia Natural.

Aparentemente las negociaciones con el Museo Nacional comenzaron en septiembre de 1936, cuando Adolfo Breyer ofrece en venta al Ministro de Justicia e Instrucción Pública, Dr. Jorge de La Torre, una colección arqueológica reunida por su fallecido hijo, Adolfo Breyer ${ }^{20}$. El material es también examinado por E. Casanova, junto con los ayudantes Santiago Gatto y Pablo Haedo. En noviembre de ese año el Director recomienda la compra, pero todo el asunto se dilata debido a desacuerdos en relación al monto solicitado y a diferentes pasos burocráticos. El 20 de noviembre de 1939, por decreto presidencial $\mathrm{N}^{\circ}$ 47.437 del Presidente Ortiz, se aprueba la compra por un valor de 12.000 pesos moneda nacional. La colección ingresó al museo en 1940 y fue catalogada en 1944. En total suman 849 entradas de catálogo.

Cotejando las 263 fichas originales que aún se conservan, pudimos establecer que, un mínimo de 184 ítems corresponderían a una colección Schreiter preexistente, pudiendo ser esta cifra significativamente mayor, dado

\footnotetext{
${ }^{20}$ Adolfo Breyer (h) y su hermano, Alberto Breyer eran miembros activos de la Sociedad Entomológica Argentina, integrando la comisión directiva en diferentes períodos. Contribuyeron con la redacción de resúmenes y artículos en la Revista de la Sociedad Entomológica Argentina con la que colaboraban también económicamente colocando publicidad de su negocio familiar: la Casa Breyer Hnos. dedicada a la música.
}
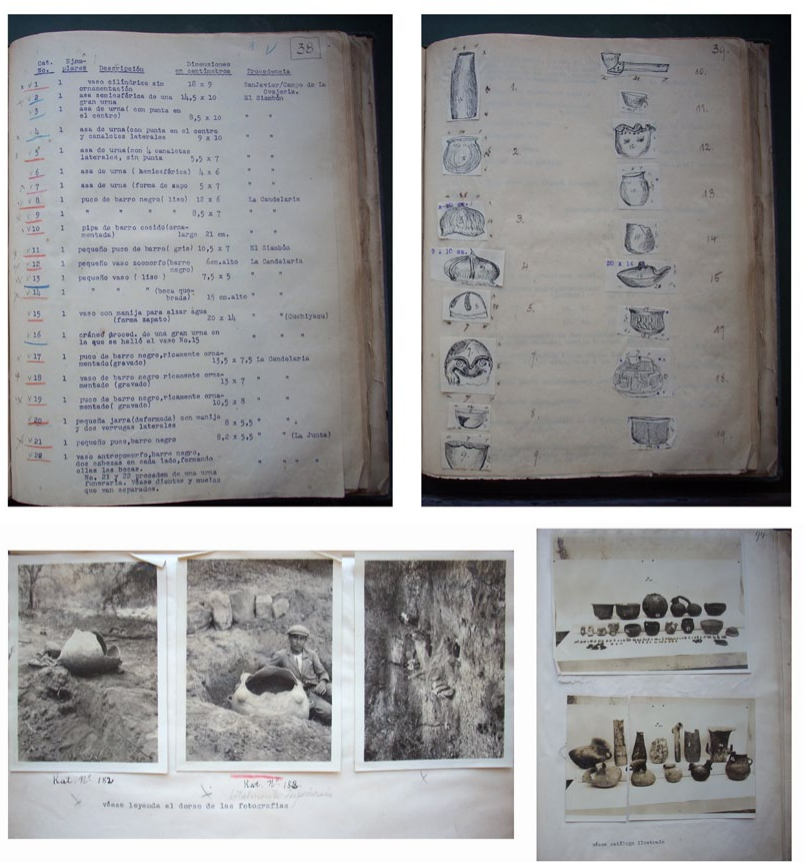

Figura 1. Cuatro páginas del catálogo original elaborado por Schreiter para el registro de la colección vendida al Museo Nacional de Historia Natural "Bernardino Rivadavia". Archivo Fotográfico y Documental MEJBA.

Figure 1. Four pages of the original catalog prepared by Schreiter for recording the collection sold to the National Museum of Natural History "Bernardino Rivadavia". MEJBA Photographic Archive and Documentary. 
que sólo se dispone del $30 \%$ de las fichas ${ }^{21}$. Con respecto a la fecha en que Breyer adquirió la colección de manos de Schreiter proponemos que el traspaso pudo ocurrir entre 1922 y 1931. El límite inicial del rango está dado por la mención en la correspondencia de Schreiter hacia Boman de unos hallazgos cerámicos en Fuerte Quemado, que él conservaba y de los cuales le envía fotografías. Boman utiliza estos datos en una publicación, en la que incluye una figura que ilustra la cerámica en cuestión (Boman 1923: 23)22. Luego pudimos observar que estas piezas integran la colección Breyer (Figura 2 a y c). El límite final lo establece una nota sobre la colección Breyer publicada por Francisco de Aparicio (de Aparicio 1931, Fig. 4 pp. 353), allí se reproduce la fotografía de un puco estilo Yocavil polícromo que, de acuerdo con la ficha, corresponde a la colección adquirida a Schreiter (Figura 2 b y d). No obstante estas fechas se mantienen por el momento en un plano conjetural, puesto que no hemos hallado correspondencia u otra documentación que dé cuenta de la transacción entre Schreiter y Breyer.

\section{Las colecciones en Tucumán}

\section{Colección Schreiter}

En el Instituto de Arqueología y Museo de la Universidad

\begin{abstract}
${ }^{21}$ En el Archivo Fotográfico y Documental del Museo Etnográfico se conservaron fichas que tenían dibujos o fotografías. La correspondencia de los objetos con una colección Schreiter se estableció gracias a la inscripción "Schreiter", "Schr.", "Sch." o "S", acompañada por un número en el ángulo inferior izquierdo de las fichas (Figura 2).
\end{abstract}

${ }^{22}$ Cartas Schreiter a Boman 12/5/1922; 28/5/1922 y Boman a Schreiter 21/5/1922, en Archivo Fotográfico y Documental MEJBA.

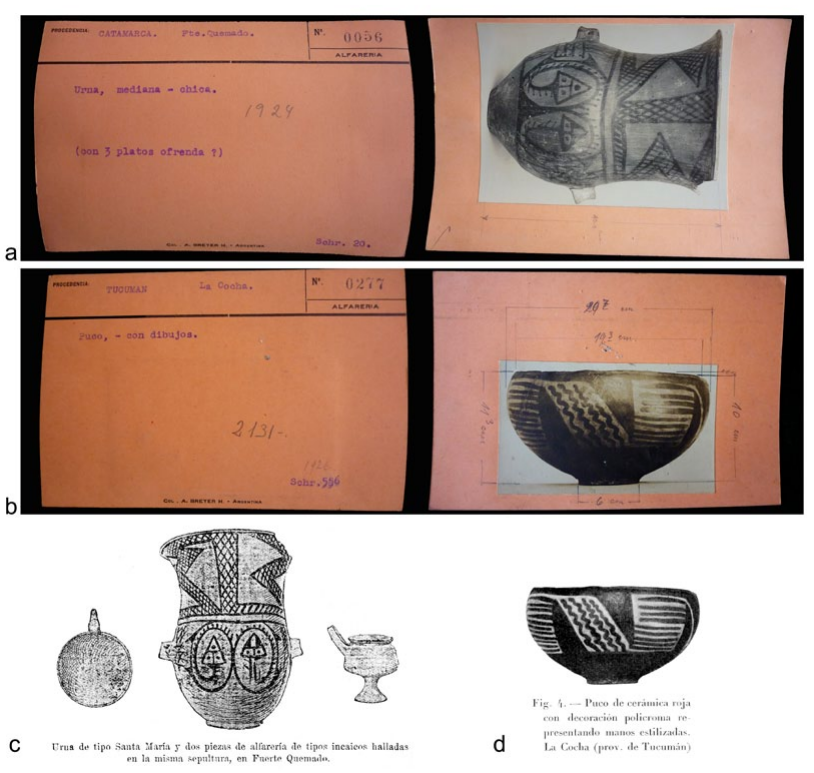

Figura 2. a y b. Anverso y reverso de fichas originales de la Colección Breyer, Archivo fotográfico y documental MEJBA. c. Ilustración en Boman (1923:23). d. Ilustración en de Aparicio (1931, Fig. 4 pp. 353).

Figure 2. a and b. Front and back of original files of the Breyer Collection, MEJBA Photographic Archives and Documentary. C. Illustration in Boman (1923: 23). d. Illustration in Aparicio (1931, Fig. 4 p. 353).
Nacional de Tucumán (IAM-UNT) existe un importante conjunto de materiales arqueológicos reunidos a partir de trabajos en el campo y adquisiciones de Schreiter en diferentes momentos. Por un lado, un conjunto de 230 objetos que componen la colección inicial del Museo de la Provincia de Tucumán, Sección Etnográfica (1916), fueron coleccionados y clasificados por Schreiter (Reyes M. Gajardo 1955:11). En este caso se trataría de materiales reunidos con anterioridad a la fundación del museo, con Ley de creación de 1908 y con decreto de organización del año $1915^{23}$ (Catálogo de Arqueología y Paleontología del Museo de la Provincia de Tucumán. Sección Etnográfica. 1916) ${ }^{24}$. Desde su organización el museo fue dirigido por Miguel Lillo y Schreiter ocupó el cargo de conservador. Por otro lado, el grupo más numeroso de objetos se compone de materiales obtenidos en el marco de expediciones organizadas por la institución en la década del 30, a diferentes puntos de Catamarca, Tucumán y Salta -valle del Cajón, valle de Hualfín, Villavil, Yocavil, Tafí, Trancas, Tafí Viejo y La Candelaria-. En la base de datos IAMUNT (2003) constan un total de 849 entradas de catálogo consignadas como "colección Schreiter", las cuales abarcan todos estos materiales.

Lamentablemente no se han conservado en el museo las libretas de viaje de los trabajos de Schreiter (E. Ribotta comunicación personal 2007). Este problema fue tempranamente mencionado por Delia Millán de Palavecino (1956: 173) ${ }^{25}$.

\section{Colección Paz Posse}

Asimismo en el IAM-UNT se encuentra la colección Paz Posse, integrada por 1852 piezas del NOA, Perú y Bolivia. Fue adquirida en 1948 por la institución, parte de ella se conforma de objetos comprados por el coleccionista tucumano Alberto Paz Posse (1913-1992) a Rudolf Schreiter. Alberto Paz Posse, terrateniente, empresario azucarero y político vinculado a la "Generación del Centenario", conformó esta colección privada de objetos arqueológicos producto de sus propias excavaciones y de la compra a terceros. En una carta de Alberto Rougés (emparentado políticamente con Paz Posse) dirigida a Ernesto Padilla, en enero de 1939 consta que: "Mucho me complace el entusiasmo con que está acrecentando su reciente colección Alberto Paz Posse. Acaba de comprar la de Don Rodolfo y, con ella, su museo ha alcanzado ya las dos mil piezas..." (Peña de Bascary 2014:1314). Schreiter, que era amigo del coleccionista desde

\footnotetext{
23 Sobre un total de 311 entradas de catálogo de la "Colección Arqueológica-Alfarería Calchaquí" (1916), 230 pueden relacionarse a adquisiciones de Schreiter.

${ }^{24}$ La historia del Museo es compleja; mudanzas, fusiones con otros organismos, reorganizaciones internas y cambios de dependencia institucional. Para una historia institucional remitirse a los trabajos de Berberián y Capuano (1974) y Arenas y Taboada (2010).

25 La autora reunió información sobre 80 contextos funerarios excavados por Schreiter en el área comprendida entre Belén y Villavil tomando notas del catálogo del museo y entrevistando a los participantes de la expedición (Millán de Palavecino 1956).
} 
mediados de la década del 30, no sólo lo acompañaba en sus travesías sino que también colaboraba con él en las descripciones técnicas de los objetos y en la gestión de nuevas adquisiciones apelando a sus contactos en los valles. Lamentablemente el catálogo de dicha colección vendida al IAM-UNT ${ }^{26}$, recientemente publicado por Peña de Bascary (2014), no especifica cuáles de los objetos pertenecían a la colección de Schreiter. Sería necesaria una investigación en el archivo familiar para tratar de hallar algún catálogo confeccionado por Schreiter que permita realizar esa discriminación.

\section{Síntesis y comentarios finales. Un panorama de las condiciones de la arqueología y el coleccionismo en la época.}

En las últimas décadas del siglo XIX y las primeras del XX los museos de Ciencias Naturales, Arqueología y Etnografía de diversas naciones de América y Europa desarrollaron estrategias para la conformación de colecciones con el fin de lograr un catálogo universal dentro de sus campos de interés. Las autoridades y encargados de áreas de los museos se ocupaban de la construcción y sostén de vínculos de carácter institucional o personal a través de los cuales circulaban información, influencias, dinero y objetos de carácter científico. La adquisición

\footnotetext{
${ }^{26}$ El catálogo es un duplicado localizado en el archivo de Alberto Paz Posse. El original, entregado al IAM-UNT se encuentra perdido (Peña de Bascary 2014).
}

por compra de colecciones por parte de museos fue una práctica corriente que fomentó el desarrollo de un mercado acotado pero floreciente. Entre los múltiples agentes involucrados en dichas redes de relaciones (Farro 2009) y logística se cuenta a funcionarios, diplomáticos, militares, científicos, sacerdotes e inclusive familiares, etc. apelando a vínculos de tipo formal e informal. Las estrategias para la adquisición de colecciones incluían la comisión de representantes institucionales que se desplazaban hacia el terreno, por lo general lejano de las metrópolis. Se desarrolla así la figura del "naturalista viajero". Estos delegados, generalmente formados en artes y ciencias, contaban con instrucciones específicas para desenvolverse en el campo con el propósito de producir elementos documentales de validación de las colecciones, de acuerdo con los estándares de la época, los que comprendían la compra de objetos coleccionables. Así las redes de relaciones integraban a los colectores locales de objetos que se ocupaban de reunir piezas para su intercambio o venta (Farro 2009; Pegoraro 2009; Podgorny 2004a y 2004b).

Hacia fines del siglo XIX y comienzos del XX en Argentina la venta de colecciones arqueológicas al extranjero era una práctica normal; no obstante, avanzado el siglo $X X$, el desarrollo de una ética nacionalista y de una noción de patrimonio en vinculación con los museos nacionales hizo de ella una actividad poco adecuada, como actividad privada, para los representantes de las ciencias locales.

\begin{tabular}{|c|c|c|c|c|}
\hline Museo & Colección & Año de adquisición & $\begin{array}{l}\text { Cantidad de } \\
\text { objetos }\end{array}$ & Precio \\
\hline $\begin{array}{l}\text { Museo Grassi de Etnología } \\
\text { (Leipzig) }\end{array}$ & Schreiter & 1907 & $\begin{array}{l}612, \\
\text { (actualmente } \\
280 \text { ) }\end{array}$ & 15.000 marcos \\
\hline \multirow{2}{*}{$\begin{array}{l}\text { Museo Real de Etnología } \\
\text { (Berlín) }\end{array}$} & Schreiter & 1908 & 33 & 1.000 marcos \\
\hline & $\begin{array}{l}\text { Herrmann- } \\
\text { Schreiter }\end{array}$ & Sin datos & 114 & Donación, sin datos \\
\hline \multirow[t]{2}{*}{ Museo del Mundo de Viena } & Schreiter & 1910 & 62 & $\begin{array}{l}700 \$ \mathrm{~m} . / \mathrm{n} . \text { o } 1736 \\
\text { coronas }\end{array}$ \\
\hline & & 1912 & 565 & $\begin{array}{l}12.500 \text { marcos o } \\
14.707 \text { coronas }\end{array}$ \\
\hline Museo de Gotemburgo & Schreiter & 1930 & 397 & Sin datos \\
\hline \multirow[t]{2}{*}{$\begin{array}{l}\text { Museo Etnográfico "Juan B. } \\
\text { Ambrosetti" (Buenos Aires) }\end{array}$} & Schreiter & $\begin{array}{l}\text { 1934-1936 (Museo Nacional } \\
\text { de Historia Natural } \\
\text { "Bernardino Rivadavia") }\end{array}$ & $\begin{array}{l}33 \\
37 \\
841\end{array}$ & $\begin{array}{l}200 \$ \mathrm{~m} . / \mathrm{n} . \\
\text { Donación } \\
4.000 \$ \mathrm{~m} . / \mathrm{n} \text {. }\end{array}$ \\
\hline & Breyer & $\begin{array}{l}1939 \text { (Museo Nacional de } \\
\text { Historia Natural } \\
\text { "Bernardino Rivadavia”) }\end{array}$ & $\begin{array}{l}849, \text { (mín. } \\
184 \text { obj. Col. } \\
\text { Schreiter) }\end{array}$ & $12.000 \$ \mathrm{~m} . / \mathrm{n}$ \\
\hline \multirow[t]{2}{*}{$\begin{array}{l}\text { Instituto de Arqueología y } \\
\text { Museo de la Universidad } \\
\text { Nacional de Tucumán }\end{array}$} & Schreiter & $\begin{array}{l}1916 \text { (Museo de la Provincia } \\
\text { de Tucumán) } \\
\text { Década del } 30\end{array}$ & 849 & Sin datos \\
\hline & Paz Posse & 1948 & $\begin{array}{l}\text { 1852, (obj. } \\
\text { Col. Schreiter } \\
\text { indet.) }\end{array}$ & Sin datos \\
\hline
\end{tabular}

Tabla 1. Síntesis de colecciones Schreiter en museos.

Table 1. Synthesis of schreiter collections in museums. 
En el Noroeste Argentino, es interesante reconocer entre los viajeros colectores de objetos arqueológicos a personalidades destacadas de las ciencias, quienes podían actuar como emisarios de los museos comisionados en expediciones o viajes de estudio en el extranjero, como Max Uhle, Georges de Crequi Monfort, Eugéne Sénéchal de la Grange, pero también a viajeros "aventureros" con menor incidencia en el campo científico y más orientados al género literario de los relatos de viajes, como Henry de La Vaulx. Importantes museos de Argentina organizaron también expediciones al NOA con el fin de reunir objetos, como es el caso de los viajes de Adolphe Methfessel, Herman ten Kate o Carlos Bruch para el Museo de La Plata o Eric Boman para el Museo Nacional o las Expediciones de la Facultad de Filosofía y Letras a cargo de Juan Bautista Ambrosetti y Salvador Debenedetti. En estos ejemplos el reconocimiento de los colectores como hombres de ciencias, junto con la documentación de hallazgos en el terreno, aportaba prestigio y valor científico a las colecciones conformadas para los museos. A pesar de la existencia de legislación específica -la promulgación en 1913 de la Ley de 9080 "Ruinas y Yacimientos Arqueológicos", reglamentada en 1921- (Endere y Rolandi 2007), los intercambios comerciales de objetos y colecciones arqueológicas a nivel local e internacional continuaron.

Fueron también muy activos los recolectores particulares entre los que destaca Manuel Zavaleta por la escala numérica de sus colecciones y sus millonarias ventas nacionales e internacionales. Estos comerciantes de antigüedades no gozaban del prestigio del hombre de ciencias que ostentaban los académicos; no obstante, existía un consenso en el ámbito de los museos que avalaba su práctica, desde el momento en que diferentes instituciones del mundo estaban dispuestas a adquirir sus colecciones.

En este escenario otro grupo de actores difícil de definir debido a la heterogeneidad en sus motivaciones, escala y resultados de sus trabajos arqueológicos e historias personales, lo constituyen buscadores de antigüedades como Schuel, Weiser, Wolters von Hauenschild o Schreiter, que a lo largo de su trayectoria fueron entrelazando la búsqueda de objetos arqueológicos, la incorporación y perfeccionamiento de pautas de registro contextual de situaciones de hallazgo, la confección de reportes de campo y artículos científicos. Cada uno de estos casos resulta muy particular y amerita estudios específicos (Balesta y Zagorodny 2000; Carrizo 2006; Lindskoug 2008).

El repaso por la historia de las colecciones arqueológicas conformadas por Schreiter nos permite comprender algunos aspectos de su rol en el campo arqueológico local. A poco tiempo de inmigrar al país e instalarse en Tucumán Rudolf Schreiter comenzó a desempeñarse con dinamismo como colector de objetos arqueológicos, desde un lugar de acción singular; con un interés genuino por la naturaleza y las antigüedades que no limitó su visión comercial del asunto. Su residencia en un medio urbano, pero relativamente cercano a los valles donde realizaba sus búsquedas le permitió colocarse en diversos lugares del circuito comercial y vincularse asimismo con el medio científico institucional, en el cual logró insertarse formalmente a través de cargos y obtener reconocimiento como hombre práctico.

La magnitud de las colecciones Schreiter y su dispersión en diferentes repositorios del ámbito nacional e internacional dan cuenta de su empeño en la búsqueda de relaciones para obtener objetos. Sabemos que sus viajes a los valles sirvieron, tanto para organizar excavaciones propias, en las cuales empleaba a lugareños para los trabajos y el transporte, como para consolidar una red de vínculos con personas que reunían para él materiales en ausencia, gracias a lo cual la suma de sus colecciones alcanza un mínimo de 3727 entradas de catálogo (Tabla 1), el número mínimo de objetos es mayor, pues muchas de éstas corresponden a lotes de objetos.

En el año 2007 tuvimos la oportunidad de entrevistar en el pueblo de Fuerte Quemado, en el valle de Santa María, al Sr. Laudino González ${ }^{27}$, nacido en la década del 30, quien conservaba vívidos recuerdos de su infancia, cuando su padre juntaba piezas arqueológicas que ocasionalmente vendía a Schreiter. Ponían los objetos en exposición, en el frente de la casa, donde él elegía cuáles llevaría. Schreiter era apreciado porque gracias a las ventas obtenían un beneficio económico, que ayudaba a sobrellevar su condición humilde. Una vez que elegía las mejores vasijas, las embalaban en canastos de madera y totora; las que sobraban eran reutilizadas para guardar el agua fresca, para cocinar y otros usos domésticos. Laudino recuerda que Schreiter tenía también arreglos con otra gente del lugar, como Francisco Villagra, Simón Pastrana o Manuel Guerra, baqueanos de Fuerte Quemado. También con comerciantes más importantes, como Simón Marcel, de Santa María, o Rodríguez Espada, de Amaicha, personas que realizaban un acopio entre los lugareños y que a su vez, vendían a Schreiter (Laudino González comunicación personal 2007) ${ }^{28}$.

En cuanto a la venta de colecciones, las breves historias narradas exhiben sus nexos con parientes y conocidos en Europa, como también con personas del ámbito de las ciencias, a partir de las que logra contactos con museos de arqueología en Europa y Argentina. Esta práctica no cejó tras su nombramiento en cargos del museo desde 1915. Se puede plantear inclusive que el contexto institucional resultó en algún momento favorable a la conformación y venta de sus colecciones privadas, si consideramos que Métraux colaboró en la gestión de la venta al museo

\footnotetext{
27 Entrevista con Laudino González, realizada en su casa en Fuerte Quemado, el 01/04/2007, por Valeria Palamarczuk.

28 El epistolario de Schreiter da cuenta de correspondencia con Simón Pastrana quien lo contacta para pedirle trabajo (Cartas $N^{\circ} 153$ 28/10/1932, No 160 14/11/1932 y No 189 16/01/1933 en Amenta 2008: 156, 160 y 182). Existe correspondencia de Schreiter hacia Pastrana recomendándole la venta de objetos arqueológicos a Paz Posse (Carta N 5 a Pastrana 3/1/1940 en Peña de Bascary 2014:16).
} 
de Gotemburgo. Es importante tener en cuenta que el mismo Métraux fue muy activo reuniendo colecciones arqueológicas y etnográficas como mecanismo para la retribución a instituciones extranjeras que financiaban sus expediciones en Argentina y Bolivia (Benedetti 2006).

En estas actividades Schreiter entraba en competencia u oposición con diferentes actores. Por un lado, con otros colectores, como lo evidencian sus críticas a la figura del conocido huaquero Zavaleta y sus temores a que éste entorpeciera alguna venta ${ }^{29}$. También con colectores de instituciones, miembros reconocidos de la esfera científica porteña como por ejemplo Salvador Debenedetti, quien lo considera como uno más entre otros "vulgares comerciantes" como Salvatierra o Zavaleta, que excavaron en el valle de Santa María ${ }^{30}$. Por otro lado, sobre el final de su desempeño en el instituto, resalta su enfrentamiento con el nuevo director, Palavecino, quien propuso una normativa institucional tendiente a limitar su actividad de coleccionista.

Varios trabajos exponen facetas de la biografía, personalidad e intereses científicos de Schreiter. En base a ellos podemos ver su derrotero, desde sus inicios como un naturalista autodidacta, con una formación de nivel medio, que alternaba actividades de gabinete y campo institucionales con trabajo por cuenta propia. En general se han resaltado aspectos positivos, como su condición de naturalista autodidacta discípulo de Miguel Lillo, o su rol -desde un lugar de hombre práctico-, de impulsor de las investigaciones arqueológicas científicas en Tucumán, siempre presente y activo en el ámbito institucional desde la fundación del Museo de Historia Natural y perdurando a través de los complejos cambios institucionales. Sobre sus breves publicaciones se ha valorado la honestidad en sus observaciones, sin pretensiones de grandeza o discusiones vanidosas. $Y$, en lo personal, se señala su carácter chispeante y picaresco, no exento de un cariz conflictivo (Amenta 2008; Arenas y Taboada 2010; Berberián y Capuano 1974; Carrizo 2006; Reyes M. Gajardo 1955). En este contexto nuestros aportes consisten en mostrar los resultados de las pesquisas con respecto a la conformación de colecciones arqueológicas por parte de Schreiter y difundir un manuscrito inédito traducido al castellano, elementos que ayudan a matizar las miradas sobre su rol en el campo de la arqueología.

Será importante a futuro completar nuestra sistematización con nuevas investigaciones sobre colecciones de museos y particulares; hemos comprobado que existen colecciones identificadas con otros nombres en museos (Ej. Paz Posse o Breyer) que nos indican la posibilidad de que

\footnotetext{
${ }^{29}$ Carta de Schreiter a Weule 04/10/1905 en Archivo del Museo Grassi de Etnología de Leipzig.

30 Una dura apreciación que Debenedetti vuelca en su libreta de campo del año 1920: "1 de Febrero.- Pasamos el día en Fuerte Quemado, buscando y reuniendo datos. Me afirman viejos vecinos de la localidad que ya se han hecho numerosas excavaciones en los cementerios de las inmediaciones. Zavaleta reunió mucho material y lo mismo Salvatierra y Schreiter. Todos estos señores resultaron vulgares comerciantes." (Libreta XVI Expedición de la Facultad de Filosofía y Letras, pp. 39, en Archivo Fotográfico y Documental MEJBA).
}

haya otras aún desconocidas ${ }^{31}$. Los documentos con información arqueológica producidos por Schreiter están en gran medida inéditos y dispersos en el mundo: trabajos manuscritos, fotografías, catálogos, croquis, mapas, diarios de viaje, epistolario. Algunos de ellos se encuentran en repositorios institucionales, de otros se ha perdido su rastro. Será muy interesante a futuro acceder y difundir estos materiales de archivo.

Buenos Aires, 15 de septiembre de 2016

\section{Agradecimientos}

A las autoridades del Museo del Mundo de Viena por facilitarnos el manuscrito y permitir su publicación traducida, especialmente a la Dra. Claudia Augustat del mismo museo. A la Dra. Christine Seige del Museo Grassi de Etnología en Leipzig, a la Dra. Manuela Fischer del Museo Real de Etnología de Berlín por su atenta disposición en la búsqueda documental. A María Isabel Scarafoni y Gabriela Ammirati del Museo Etnográfico "Juan B. Ambrosetti". Al Sr. Laudino González. A los Lic. Eduardo Ribotta y Sergio Carrizo del Instituto de Arqueología y Museo, Universidad Nacional de Tucumán. A la Lic. Sara Amenta. A la Lic. Alejandra Reynoso, a los evaluadores anónimos y editores por sus comentarios sobre una primera versión del texto.

\section{Bibliografía}

Amenta, S.G. 2008. Carlos Rodolfo Schreiter (1877-1942). Notas biográficas y epistolario de un naturalista, Fundación Miguel Lillo, Tucumán.

Arenas, P. 1991. Antropología en la Argentina. El aporte de los científicos de habla alemana. Institución Cultural Argentino - Germana y Museo Etnográfico J. B. Ambrosetti, FFyL, UBA, Buenos Aires.

Arenas, P. 1998. Alfred Métraux: Momentos de su paso por Argentina. Mundo de Antes 1: 121-144.

Arenas, P. y C. Taboada. 2010. De Instituto de Etnología a Instituto de Arqueología y Museo: un tramo de su historia. En P. Arenas, C.A. Aschero y C. Taboada Eds.: Rastros en el camino... Trayectos e identidades de una Institución. Homenaje a los 80 años del IAM-UNT, 6:43-70, EDUNT, Tucumán.

Balesta, B. y N. Zagorodny. 2000. Memorias e intimidades de una colección arqueológica. Relaciones de la SAA XXV: 41-50.

Becker-Donner, E. 1950. Die Nordwestargentinischen Sammlungen des Wiener Museums für Völkerkunde. I Teil. Archiv für Völkerkunde, Band V: 1-102.

Becker-Donner, E. 1952. Die Nordwestargentinischen Sammlungen des Wiener Museums für Völkerkunde. II (Schluß-) Teil. Archiv für Völkerkunde, Band VI-VII: 229-362.

Becker-Donner, E. 1953. Nichtkeramische Kulturfunde Nordwest- argentiniens. Aus den Sammlungen des Wiener Museums für Völkerkunde. Archiv für Völkerkunde Band VIII: 273-324.

Benedetti, C. M. 2006. Antropología y formación de colecciones:

\footnotetext{
31 Del epistolario Schreiter-Boman surgen sus intentos de establecer contactos con compradores potenciales: 28/7/1921 Sr. Gardner; 23/5/1923 Sr. Farabe del Consulado Norteamericano; 5/9/1924 Mr. Heye. Desconocemos los resultados de estas gestiones. Cartas en el Archivo Fotográfico y Documental MEJBA.
} 
las producciones artesanales del pueblo chané, Runa XXVI: 247-262.

Berberián, E. y E. Capuano. 1974. El Instituto de Antropología de la Universidad Nacional de Tucumán. Sus etapas y aportes a la cultura argentina, Ediciones Cabargón, Buenos Aires.

Boman, E. 1920. Cementerio indígena en Vilucó (Mendoza), posterior a la conquista. Anales del Museo Nacional de Historia Natural de Buenos Aires, T. XXX: 501-562.

Boman, E. 1923. Los ensayos de establecer una cronología prehispánica en la Región Diaguita (República Argentina). Boletín de la Academia Nacional de Historia, VI, (15-17): 1-31, Quito.

Carrizo, S. 2006. Carlos Rodolfo Schreiter: generador de la tarea arqueológica en la provincia de Tucumán. En: Actas de las VI Jornadas: La Generación del Centenario y su proyección en el Noroeste Argentino (1900-1950), 200-208.

Carrizo, S. 2010. Documentos, quipus, clases e indios. Andrés Radamés Altieri en el Instituto De Antropología de la Universidad Nacional De Tucumán. Revista del Museo de Antropología 3: 239-250.

Catálogo de Arqueología y Paleontología del Museo de la Provincia de Tucumán. Sección Etnográfica. 1916. Imp. Prebisch y Violetto, Tucumán.

de Aparicio, F. 1931. Colecciones privadas. La colección Adolfo Breyer. Solar: 349-355.

Endere, M. L. y D. Rolandi. 2007. Legislación y gestión del patrimonio arqueológico. Breve reseña de lo acontecido en los últimos 70 años. Relaciones de la SAA XXXII: 33-54.

Farro, M.E. 2009. La formación del Museo de La Plata. Coleccionistas, comerciantes, estudiosos y naturalistas viajeros a fines del siglo XIX. Prohistoria. Rosario.

Heger, F. 1913. Altertümer der Diaguitas. International Congress of Americanists. Proceedings of the XVIII Session. Part II: 293297. Londres.

IAMUNT. 2003. Base de datos de la colección arqueológica. Tucumán: Fundación Tiempo / Fundación CEPPA.

Isacsson, S. E. 1999. Una nota retrospectiva del editor general. Eds. P. Stenborg y A. Muñoz. Masked Histories. A Re-examination of the Rodolfo Schreiter Collection from North-western Argentina. Etnologiska Studier 43: 9-11, Etnografiska Museet I Göteborg.

Jahrbuch des Museums für Völkerkunde zu Leipzig. 1907. R. Voigtländers, Leipzig.

Kühn, F. y G. Rohmeder. 1943. Estudio Fisiográfico de las Sierras de Tucumán. Instituto de Estudios Geográficos, UNT, Tucumán.

Lindskoug, H. B. 2008. En la sombra de la arqueología argentina: Jorge von Hauenschild y la formación de la colección von Hauenschild del Museo de Antropología (Universidad Nacional de Córdoba). Revista del Museo de Antropología 1(1): 61-70.

Métraux, A. 1930. Expedición arqueológica a La Candelaria (Provincia de Salta). Journal de la Société des Américanistes. Vol 22, N²: 402-404.

Millán de Palavecino, M.D. 1956. Notas sobre tecnología arqueológica (la colección Schreiter de Catamarca). Revista de la Facultad de Ingeniería Química. Vol. XXV: 173-189.
Pegoraro, A. 2009. "Las colecciones del Museo Etnográfico de la Universidad de Buenos Aires: un episodio en la historia del americanismo en la Argentina 1890-1927"., FFyL, UBA, Argentina, 445 pp. Tesis de Doctorado.

Peña de Bascary, S. 2014. La colección arqueológica Alberto Paz Posse. Historia y Cultura. Boletín N 1, Fund. M. Lillo, Tucumán.

Podgorny, I. 2004a. Antigüedades incontroladas. La arqueología en la Argentina, 1910-1940. Comps.: F. Neiburg y M. Plotkin, Intelectuales y expertos. La constitución del conocimiento social en la Argentina, 147-174, Paidós, Buenos Aires.

Podgorny, I. 2004b. Tocar para creer. La arqueología en la Argentina, 1910-1940, Anales del Museo de América, 12: 147-82.

Primera Reunión Nacional de la Sociedad Argentina de Ciencias Naturales, Tucumán, 1916. 1919, Imprenta Coni, Buenos Aires.

Reyes M. Gajardo, C. 1955. Don Carlos Rodolfo Schreiter. Recordación a los 13 años de su muerte (1942-1955). Cuadernos de Extensión Universitaria 13: 7-19.

Schreiter, R. 1919. Distintas clases de sepulturas antiguas observadas en los Valles Calchaquies. Sonderabdruck aus Zeitschrift des Deutschen Wissenschaftlichen Vereins zur Kulturund Landeskunde Argentiniens: 1-11.

Schreiter, R. 1928. Monumentos Megalíticos y Pictográficos en los altivalles de la provincia de Tucumán. Boletín del Museo de Historia Natural de la Univ. Nacional de Tucumán, Vol. $2 \mathrm{~N}^{\circ} 1$.

Schreiter, R. 1934. La civilisation de La Candelaria et son extension dans la Province de Tucumán. Journal de la Societé des Américanistes Nouv. Série, Tomo XXVI. (1): 53-65.

Schreiter, R. 1936a. Enterratorios indígenas en las grutas de Villavil. Departamento de Belén (Catamarca). Boletín del Museo de Historia Natural. Tomo II, (7-11): 3-8 y 16 láminas. Museo de Historia Natural, UNT. Tucumán.

Schreiter, R. 1936b. Nota preliminar sobre una exploración arqueológica en la Loma de La Florida. Corral Quemado, Departamento de Belén (Catamarca). Febrero-abril de 1934. Enterratorios indígenas con alfarería draconiana. Boletín del Museo de Historia Natural, Tomo II, (7): 9-16. Museo de Historia Natural, UNT. Tucumán.

Steindachner, F. 1910-1911. Annalen K. K. Naturhistorischen Hofmuseums. XXIV Band: 53-70. A. Hölder. K. und K. Hof- und Universitäts-Buchhändler, Buchhändler der Kaiserlichen Akademie der Wissenschaften, Viena.

Steindachner, F. 1912. Notizen. Jahresbericht für 1911. Annalen K. K. Naturhistorischen Hofmuseums. XXVI Band. A. Hölder. K. und K. Hof- und Universitäts-Buchhändler, Buchhändler der Kaiserlichen Akademie der Wissenschaften, Viena.

Stenborg, P. 1999. Background to the Acquisition of the Collection. Eds. P. Stenborg y A. Muñoz. Masked Histories. A Re-examination of the Rodolfo Schreiter Collection from Northwestern Argentina. Etnologiska Studier 43: 135-145, Etnografiska Museet I Gotemburgo.

Weiser, V. 1920. Libreta 16 de la III Expedición Benjamín Muñiz Barreto. MS. División Arqueología, Museo de La Plata.

\section{Obituarios}

1942. Revista Argentina de Agronomía. Tomo 9: 175.

1943. Revista de la Soc. Entom. Argentina. Tomo XII (1): 56-57. 